\title{
Differentiation of gonococcal and non-gonococcal neisseriae by the superoxol test
}

\author{
H YOUNG,* A B HARRIS,* AND J W TAPSALLt \\ From the *Department of Bacteriology, Edinburgh University Medical School, and the + Prince of Wales \\ Hospital, Randwick, New South Wales, Australia
}

SUMMARY We evaluated the superoxol (catalase) test as a means of differentiating gonococci from related species of organisms which were cultured from a variety of anatomical sites. An isolate was almost certainly not a gonococcus if it gave a negative superoxol test result, as all but one of 596 available gonococci gave positive test results. However, a proportion of the nongonococcal neisseriae and isolates of Branhamella catarrhalis, also gave positive test results. The superoxol test is thus a useful addition to the techniques available for the characterisation of gonococci, but additional procedures are needed to confirm the identities of isolates giving positive results.

\section{Introduction}

The isolation of gonococcal and non-gonococcal neisseriae and other related organisms from genital and extragenital sites makes it necessary to distinguish the clinically important isolates. Carbohydrate degradation tests, serological techniques, or both may be used. Where laboratories perform only conventional carbohydrate utilisation tests or fluorescent antibody tests, however, identification of certain Neisseria gonorrhoeae cultures may pose problems. Arko et al found that $N$ meningitidis and Branhamella catarrhalis were the two organisms most often confused with $N$ gonorrhoeae. ' Coagglutination is useful in identifying gonococci from anogenital sites in women and from the urethra in men. ${ }^{2}$ The frequent occurrence of meningococci in the anorectum of homosexual men ${ }^{3}$ and in the pharynx limits the value of coagglutination in identifying isolates from these sites because of cross reactivity. Recently Saginur et al described a simple, rapid, low cost screening test for gonococci, the superoxol (catalase) test, ${ }^{4}$ which was more reliable than coagglutination.

The rationale of the superoxol test was provided by Norrod and Morse, 5 who found increased levels of catalase in gonococci compared with other neisseriae. Gonococci could be differentiated from meningococci by using $20 \%$ or $30 \%$ hydrogen peroxide (superoxol test) but not by the conventional catalase test with $3 \%$ hydrogen peroxide. ${ }^{4}$ Although results

Address for reprints: Dr H Young, Department of Bacteriology, Edinburgh University Medical School, Teviot Place, Edinburgh EH8 9AG

Accepted for publication 13 September 1983 were not analysed in relation to culture source, a positive superoxol test result on an isolate growing on Thayer-Martin medium was considered strongly indicative of $N$ gonorrhoeae. As various nongonococcal neisseriae also gave superoxol positive results, however, biochemical confirmation was necessary. Owing to the high sensitivity of the test, a negative superoxol result was considered to mean that an isolate was not gonococcal. We evaluated the superoxol test in Edinburgh and Sydney with specific reference to the anatomical source of cultures.

\section{Patients and methods}

In Edinburgh, genital or anogenital and pharyngeal material from patients attending the department of genitourinary medicine of the Royal Infirmary was inoculated directly on to modified New York City (MNYC) medium, ${ }^{6}$ and transported to the laboratory within four hours. Cultures were incubated for 24 hours, and any suspected neisserial colonies were tested by touching the colony with a cotton bud soaked in oxidase reagent; oxidase positive bacteria turn the contact area of the bud purple within five to 15 seconds. If colonies were oxidase positive, identical ones were Gram stained and examined by the superoxol test. If both urethral and cervical cultures were oxidase positive only those from one site, usually the cervix, were examined by the superoxol test. Oxidase positive Gram negative diplococci (GNDC) were further identified by the rapid carbohydrate utilisation test, ${ }^{7}$ and also on occasions by coagglutination. ${ }^{2}$ Cultures giving negative reactions were re-examined after incubation for 48 hours. 
STOCK CULTURES

The following stock cultures were also examined by the superoxol test: 16 maltose negative variants of $N$ meningitidis serogroup B (kindly supplied by Dr J A Saez Nieto, servicio de bacteriologia, Centro Nacional de Microbiologia, Virologia, y Immunologia Sanitarias, Majadahonda, Madrid), and 13 strains of $\beta$-lactamase producing $B$ catarrhalis isolated from sputum specimens submitted to the clinical bacteriology laboratory of Edinburgh University Medical School for microbiological investigation.

In Sydney, material obtained from patients attending the sexually transmitted diseases clinic at the Prince of Wales Hospital was inoculated onto MNYC medium. After incubation for 24 and 48 hours suspected neisserial colonies were Gram stained and an oxidase test was performed. As a check for purity oxidase positive GNDC were subcultured onto a horse blood medium lysed with saponin which was suitable for obtaining inocula for rapid carbohydrate utilisation tests ${ }^{8}$ and also on to chocolate agar for the superoxol test. Isolates were identified by a rapid carbohydrate utilisation test. ${ }^{8}$

\section{SUPEROXOL TEST}

In Sydney the superoxol test was performed as described by Saginur et al. ${ }^{4}$ A drop of $30 \%$ hydrogen peroxide was added to the bacterial colonies to be tested; a positive superoxol test result was defined as an immediate (less than one second delay) and abundant production of bubbles, and a negative result by delayed or weak bubbling. Intermediate reactions were scored as equivocal.

In Edinburgh a few colonies of the culture to be tested were picked from the primary isolation plate with a loop and emulsified directly in a drop of $30 \%$ hydrogen peroxide placed in the centre of a clean glass slide. A positive superoxol test result was defined as abundant production of bubbles occurring within two to three seconds of starting emulsification. A negative reaction was defined by weak or delayed bubbling after three seconds, and intermediate reactions were scored as equivocal.

\section{Results}

In Edinburgh during a four month period, 430 oxidase positive colonies growing on MNYC medium were examined by the superoxol test and were Gram stained; and $\mathbf{4 0 2}$ were shown to be GNDC. The other 28 were Gram negative bacilli, and were not investigated further $(27(96.4 \%)$ of them were from throat cultures.) Table I shows the results of the superoxol test applied to GNDC isolated from various anatomical sites.

Of the 252 isolates confirmed as being $N$ gonorrhoeae by the rapid carbohydrate utilisation test, $251(99.6 \%)$ gave positive results to the superoxol test. Eight $(5 \cdot 3 \%)$ of the 150 non-gonococcal neisseriae also gave positive superoxol test results. Of the 150 non-gonococcal neisseriae, 133 $(88 \cdot 7 \%)$ were identified as $N$ meningitidis, $13(8 \cdot 7 \%)$ as $N$ lactamica, two $(1 \cdot 3 \%)$ as $N$ perflava and two $(1 \cdot 3 \%)$ as $B$ catarrhalis. Four $(3.0 \%)$ of the meningococcal isolates and three $(23 \cdot 1 \%)$ of the $N$ lactamica isolates gave positive superoxol test results. None of the 16 maltose negative variants of meningococci gave positive superoxol test results, whereas six $(46 \cdot 5 \%)$ of the $13 \beta$-lactamase producing strains of $B$ catarrhalis isolated from sputum samples gave positive results. The 16 maltose negative meningococci gave a positive maltose reaction in the rapid carbohydrate test.

In Sydney 387 oxidase positive GNDC isolates were examined from July 1982 to February 1983. Table II shows the results of the superoxol test applied to these strains. All but one of 344 isolates confirmed as $N$ gonorrhoeae by the rapid carbohydrate utilisation test gave positive superoxol test

TABLE I SUperoxol test applied to 402 oxidase positive Gram negative diplococci isolated from patients attending the department of genitourinary medicine, Edinburgh

\begin{tabular}{|c|c|c|c|c|c|}
\hline \multirow{2}{*}{$\begin{array}{l}\text { Identity (by } \\
\text { rapid carbohydrate } \\
\text { utilisation test) }\end{array}$} & \multirow[b]{2}{*}{ Source } & \multirow{2}{*}{$\begin{array}{l}\text { No of } \\
\text { lsolates }\end{array}$} & \multicolumn{3}{|c|}{ Superoxol test results: } \\
\hline & & & Positive & Negative & Equivocal \\
\hline Neisseria gonorrhoeae & $\begin{array}{l}\text { Urethra } \\
\text { Cervix } \\
\text { Rectum } \\
\text { Throat }\end{array}$ & $\begin{array}{r}129 \\
57 \\
37 \\
29\end{array}$ & $\begin{array}{r}128 \\
57 \\
37 \\
29\end{array}$ & $\begin{array}{l}1 \\
0 \\
0 \\
0\end{array}$ & $\begin{array}{l}0 \\
0 \\
0 \\
0\end{array}$ \\
\hline Neișseria meningitidis & $\begin{array}{l}\text { Urethra } \\
\text { Cervix } \\
\text { Rectum } \\
\text { Throat }\end{array}$ & $\begin{array}{r}1 \\
1 \\
2 \\
129\end{array}$ & $\begin{array}{l}0 \\
0 \\
0 \\
4\end{array}$ & $\begin{array}{r}1 \\
1 \\
2 \\
124\end{array}$ & $\begin{array}{l}0 \\
0 \\
0 \\
1\end{array}$ \\
\hline $\begin{array}{l}\text { Neisseria lactamica } \\
\text { Neisseria perflava } \\
\text { Branhamella catarrhalis } \\
\quad \text { Total }\end{array}$ & $\begin{array}{l}\text { Throat } \\
\text { Throat } \\
\text { Throat }\end{array}$ & $\begin{array}{r}13 \\
2 \\
2 \\
402\end{array}$ & $\begin{array}{r}3 \\
0 \\
1 \\
259\end{array}$ & $\begin{array}{r}10 \\
2 \\
1 \\
142\end{array}$ & $\begin{array}{l}0 \\
0 \\
0 \\
1\end{array}$ \\
\hline
\end{tabular}


TABLE II Superoxol test applied to 387 oxidase positive Gram negative diplococci isolated from patients attending the sexually transmitted diseases clinic at the Prince of Wales Hospital, Sydney

\begin{tabular}{|c|c|c|c|c|c|}
\hline \multirow{2}{*}{$\begin{array}{l}\text { Identity (by } \\
\text { rapid carbohydrate } \\
\text { utilisation test) }\end{array}$} & \multirow[b]{2}{*}{ Source } & \multirow{2}{*}{$\begin{array}{l}\text { No of } \\
\text { Isolates }\end{array}$} & \multicolumn{3}{|c|}{ Superoxol test results: } \\
\hline & & & Positive & Negative & Equivocal \\
\hline Neisseria gonorrhoeae & $\begin{array}{l}\text { Urethra } \\
\text { Cervix } \\
\text { Rectum } \\
\text { Throat } \\
\text { Eye }\end{array}$ & $\begin{array}{r}261 \\
52 \\
14 \\
16 \\
1\end{array}$ & $\begin{array}{r}260 \\
52 \\
14 \\
16 \\
1\end{array}$ & $\begin{array}{l}0 \\
0 \\
0 \\
0 \\
0\end{array}$ & $\begin{array}{l}1 \\
0 \\
0 \\
0 \\
0\end{array}$ \\
\hline $\begin{array}{l}\text { Neisseria meningitidis } \\
\text { Neisseria lactamica } \\
\text { Neisseria perflava } \\
\text { Branhamella catarrhalis } \\
\quad \text { Total }\end{array}$ & $\begin{array}{l}\text { Throat } \\
\text { Throat } \\
\text { Throat } \\
\text { Throat }\end{array}$ & $\begin{array}{r}34 \\
2 \\
1 \\
6 \\
387\end{array}$ & $\begin{array}{r}4 \\
2 \\
1 \\
4 \\
354\end{array}$ & $\begin{array}{r}30 \\
0 \\
0 \\
2 \\
32\end{array}$ & $\begin{array}{l}0 \\
0 \\
0 \\
0 \\
1\end{array}$ \\
\hline
\end{tabular}

results. One strain gave an equivocal result, but was positive on repeat testing. Of the 43 non-gonococcal isolates, $34 \mathbf{( 7 9 \% )}$ ) were meningococci, of which four gave positive superoxol test results. Four of six strains of $B$ catarrhalis, both isolates of N lactamica, and the single isolate of $N$ perflava gave positive results to the superoxol test.

\section{Discussion}

These results confirm the findings of Saginur et al ${ }^{4}$ regarding the sensitivity of the superoxol test in indentifying $N$ gonorrhoeae, with only one of 596 gonococci tested giving a negative result. The test is therefore valuable in screening for gonococcal colonies on culture plates. It should be noted, however, that the superoxol test is not specific for $N$ gonorrhoeae, so that while a negative test result virtually excludes the possibility of an isolate being a gonococcus, other means are required to identify all isolates giving positive results. The Gram stain and oxidase tests are necessary procedures in this process, and either coagglutination or carbohydrate utilisation tests would provide satisfactory confirmation for urethral isolates in men or for strains from genital sites in women. ${ }^{2}$

This study has shown, however, that the superoxol test is of less value for identifying isolates from the pharynx and rectum, as it gives positive results with a considerable number of meningococci, other neisseriae, and the related $B$ catarrhalis. These organisms may be isolated on selective media ${ }^{9}$ and were grown on the media used in this study. It has been shown that the value of coagglutination in identifying strains from the pharynx and the rectum is reduced by cross reactivity between gonococci and other organisms. ${ }^{2}$ Rapid carbohydrate utilisation tests would, however, appear to be particularly useful for strains from these sites. ${ }^{18}$ This is supported by the finding that meningococci, which are maltose negative by conventional growth dependent degradation tests, are maltose positive by the rapid utilisation tests. Odugbemi and Arko found a negative superoxol test result valuable in differentiating Kingella denitrificans from $N$ gonorrhoeae. ${ }^{10} \mathrm{~K}$ denitrificans has a colonial morphology very similar to that of the gonococcus, is coccoid to rod shaped, and produces acid from glucose. The superoxol test therefore seems to be a useful procedure for identifying gonococci if it is used in conjunction with currently available techniques and its limitations are recognised.

\section{References}

1. Arko RJ, Finley-Price KG, Wong KH, Johnson SR, Reising G. Identification of problem Neisseria gonorrhoeae cultures by standard and experimental tests. J Clin Microbiol 1982; 15:435-8.

2. Young H, McMillan A. Rapidity and reliability of gonococcal identification by coagglutination after culture on modified New York City medium. Br J Vener Dis 1982;58: 109-12.

3. McMillan A Young $\mathbf{H}$. Gonorrhea in the homosexual man: frequency of infection by culture site. Sex Transm Dis 1978; $5: 146-50$.

4. Saginur R, Clecner B, Portnoy J, Mendelson J. Superoxol (catalase) test for identification of Neisseria gonorrhoeae. $J$ Clin Microbiol 1982; 15:475-6.

5. Norrod P, Morse SA. Absence of superoxide dimutase in some strains of Neisseria gonorrhoeae. Biochem Biophys Res Commun 1979;90: 1287-94.

6. Young $\mathrm{H}$. Cultural diagnosis of gonorrhoea with modified New York City (MNYC) medium. Br J Vener Dis 1978; 54:36-40.

7. Young H, Paterson IC, McDonald DR. Rapid carbohydrate utilisation test for the identification of Neisseria gonorrhoeae. Br J Vener Dis 1976; 52:172-5.

8. Tapsall JW, Cheng J. Rapid identification of pathogenic species of Neisseria by carbohydrate degradation tests. Importance of glucose in media for preparation of inocula. $\mathrm{Br}$ $J$ Vener Dis 1981:57:249-52.

9. Doern GV, Morse SA. Branhamella (Neisseria) catarrhalis: criteria for laboratory identification. J Clin Microbiol 1980;11:193-5.

10. Odugbemi T, Arko RJ. Differentiation of Kingelle denitrificans from Neisseria gonorrhoeae by growth on a semisolid medium and sensitivity to amylase. J Clin Microbiol 1983; 17:389-91. 